\title{
Availability of interventional-radiological revascularization procedures in Germany - an analysis of the DeGIR Registry Data 2018/19
}

\section{Versorgungslage mit interventionell-radiologischer Gefäßrevaskularisation in Deutschland - eine Analyse der DEGIR-Registerdaten 2018/19}

Authors

Andreas H. Mahnken', Jonathan Nadjiri², Balthasar Schachtner ${ }^{3}$, Arno Bücker ${ }^{4}$, Lothar J. Heuser ${ }^{5}$, Dominik Morhard ${ }^{6}$, Peter Landwehr ${ }^{7}$, Ralf-Thorsten Hoffmann ${ }^{8}$, Ansgar Berlis ${ }^{9}$, Marcus Katoh ${ }^{10}$, Peter Reimer ${ }^{11}$, Michael Ingrisch ${ }^{12}$, Philipp Paprottka ${ }^{13}$

\section{Affiliations}

1 Diagnostic \& Interventional Radiology, Philipps-University Marburg, Germany

2 Department of Interventional Radiology, Klinikum rechts der Isar of the Technical University of Munich, Germany

3 Department of Radiology, Ludwig-Maximilians-Universität München, Munich, Germany

4 Clinic of Diagnostic and Interventional Radiology, Saarland University Medical Center, Homburg, Germany

5 Diagnostic and Interventional Radiology, Ruhr-Universität Bochum, Germany

6 Radiology and Neuroradiology, Leopoldina-Krankenhaus der Stadt Schweinfurt GmbH, Schweinfurt, Germany

7 Department for Diagnostic and Interventional Radiology, Diakoniekrankenhaus Henriettenstiftung, Hannover, Germany

8 Inst. u. Pk. f. Radiologische Diagnostik, Medizinische Fakultät Carl Gustav Carus an der TU Dresden, Germany

9 Diagnostische und Interventionelle Neuroradiologie, Neurozentrum, Augsburg, Germany

10 Diagnostische und Interventionelle Radiologie, HeliosKlinikum Krefeld, Germany

11 Zentralinstitut für bildgebende Diagnostik, Städtisches Klinikum Karlsruhe, Germany

12 Josef Lissner Laboratory for Biomedical Imaging, Institute for Clinical Radiology, Ludwig Maximilians University Hospital Munich, Germany, Munich, Germany

13 Sektion für Interventionelle Radiologie, Klinikum rechts der Isar der Technischen Universität München, Germany

Key Words

DeGIR registry data, module $A$, nationwide availability, interventional radiology, peripheral artery disease, revascularization

received 31.03 .2021

accepted 13.06.2021

published online 04.08 .2021
Bibliography

Fortschr Röntgenstr 2022; 194: 160-168

DOI 10.1055/a-1535-2774

ISSN 1438-9029

(C) 2021. Thieme. All rights reserved.

Georg Thieme Verlag KG, Rüdigerstraße 14,

70469 Stuttgart, Germany

Correspondence

Prof. Andreas H. Mahnken

Diagnostic \& Interventional Radiology, Philipps-University

Marburg, Baldingerstraße, 35043 Marburg, Germany

Tel.: +49/6421/5866230

mahnken@med.uni-marburg.de

\section{ABSTRACT}

Purpose Peripheral artery disease (PAD) is a common condition with high socio-economic relevance. Therefore, qualified nationwide provision of interventional treatments of PAD is important for maintaining a high quality medical service in Germany.

Materials and Methods All data on revascularization procedures from the quality management system of the German interventional radiological society (DeGIR) for the years 2018 and 2019 were retrospectively analysed. Number and distribution of DeGIR certified endovascular specialists and treatment centres was mapped. Documented procedures were broken down to the level of administrative districts. Absolute number of revascularization procedures and normalized number per one million inhabitants were computed.

Results In 2019 there were 57732 revascularization procedures from 228 participating centres performed by DeGIR certified interventional radiologists. A median of 62 recanalization procedures were documented per centre. 36 centres were considered to be high volume centres, with more than 500 procedures each. On a regional level in the years 2018 and 2019 combined a median (range) of 2324 (323-12518) revascularization procedures per administrative district were performed by DeGIR certified interventional radiologist. 
Conclusion There is a comprehensive nationwide high quality interventional-radiology service for the provision of revascularization procedures available in Germany.

\section{Key points:}

- In Germany there is a nationwide comprehensive infratsructure for the interventional-radiological treatment of PAD

- The volume of interventional-radiological treatments for PAD is growing

- There is a sufficient number of training and treatment centres for the delivery of interventional radiology procedures

\section{Citation Format \\ - Mahnken AH, Nadjiri J, Schachtner B et al. Availability of interventional-radiological revascularization procedures in Germany - an analysis of the DeGIR Registry Data 2018/19. Fortschr Röntgenstr 2022; 194: 160-168}

\section{ZUSAMMENFASSUNG}

Einleitung Die periphere arterielle Verschlusskrankheit ist eine häufige, sozioökonomisch bedeutsame Erkrankung. Die qualifizierte flächendeckende Versorgung mit interventionellen Therapieangeboten für Patienten mit pAVK ist daher von besonderer Bedeutung für die medizinische Versorgungsqualität in Deutschland.
Material und Methode Die Daten der Jahre 2018 und 2019 des Qualitätssicherungsregisters für interventionelle Therapien der Deutschen Gesellschaft für Interventionelle Radiologie (DeGIR) für das Modul A (gefäßeröffnende und gefäßrekonstruierende Verfahren) wurden analysiert. Zahl und Verteilung zertifizierter interventioneller Radiologen der DeGIR für Gefäßmedizin und entsprechende Behandlungszentren wurden erfasst. Es erfolgte eine Aufschlüsselung der dokumentierten Interventionen nach Regionen bis auf Ebene der Regierungsbezirke. Es wurden absolute Zahlen sowie auf 1 Million Einwohner normierte Zahlen bestimmt.

Ergebnisse Im Jahr 2019 wurden an 228 teilnehmenden Einrichtungen 57732 interventionell-radiologisch erbrachte Eingriffe im Modul A dokumentiert. Im Jahr 2019 wurden im Median 162,0 Eingriffe je Zentrum dokumentiert. Davon waren 36 Einrichtungen „High Volume“-Zentren mit mehr als 500 dokumentierten Eingriffen pro Jahr. Auf Ebene der Regierungsbezirke wurden 2018 und 2019 zusammengenommen im Median (Bandbreite) 2324 (323-12518) interventionellradiologische Gefäßrevaskularisationen je Regierungsbezirk dokumentiert.

Schlussfolgerung Die qualitätsgesicherte Versorgung mit interventionell-radiologischen Prozeduren zur Gefäßrevaskularisation durch zertifizierte interventionelle Radiologen ist in Deutschland flächendeckend verfügbar.

\section{Introduction}

According to German federal health reporting, diseases of the arteries, arterioles and capillaries (ICD10: 170-179) accounted for nearly 270000 cases of disease in 2019. With more than 190000 cases, atherosclerosis of the extremity arteries (ICD10: 170.2) comprises the largest group. Accordingly, peripheral arterial disease (PAD) is one of the most common diseases in Germany [1].

The incidence and prevalence of PAD is strongly age- and sexdependent; two-thirds of those affected are men. The age-specific number of cases per 100000 inhabitants increases from 211 in the cohort aged 45 to under 65 to 782 for those aged 65 or older. In Germany, the prevalence of PAD, defined as an ankle-brachial index $(A B I)<0.9$, is reported to be $19.8 \%$ in men and $16.8 \%$ in women aged $\geq 65$ years [2]. Comparable data from Sweden also show a prevalence of PAD of $18 \%$ in the $60-90$-year-old cohort. Here, too, the age-dependency of the disease could be impressively demonstrated, with a prevalence of $7.9 \%$ in 60-65-yearolds compared to $47.2 \%$ in the $85-90$-year-old age group [3]. A recent study showed that PAD accounted for $26.7 \%$ of all inpatient hospital admissions for vascular disease in Portugal. It is particularly noteworthy that almost $50 \%$ of patients with a diagnosis of PAD were hospitalized due to emergency [4].

According to older estimates, it is assumed that in $5-10 \%$ of patients with PAD the disease progresses to critical limb ischemia within 5 years, while $1-3 \%$ of patients present with critical ischemia at the initial onset. The progression of PAD is closely associated with typical cardiovascular risk factors, especially nico- tine abuse and diabetes mellitus [5-7]. From the financial standpoint, it is also a highly relevant disease that cost 2.56 billion euros for hospital treatment in Germany in 2009 alone [8].

Qualified, comprehensively available care for this disease, very important from a medical and economic point of view, is therefore of great significance. To this end, the German Society for Interventional Radiology and Minimally Invasive Therapy (DeGIR), together with the German Society for Neuroradiology (DGNR), has established a systematic qualification, examination and certification system $[9,10]$. Furthermore, within the framework of a quality assurance program of these professional societies, corresponding data have been collected in a voluntary registry for more than 25 years. The significance of the registry and effectiveness of interventional radiological services in Germany have already been impressively demonstrated for both stroke care and embolization treatments $[11,12]$. The aim of this article is to analyze the extent of available interventional radiological care employing revascularization procedures in Germany with expertise certified according to the DeGIR/DGNR qualification program.

\section{Materials and Methods}

The analysis is based on 2018 and 2019 registry data collected with the DeGIR/DGNR quality assurance software (samedi $\mathrm{GmbH}$, Berlin, Germany). For this purpose, the entries of Module $A$, which includes all revascularization and vascular reconstructive interventional procedures, were used as a surrogate for revascu- 
larization in PAD after removal of the interventions on the aorta from the DeGIR/DGNR registry. All data were analyzed without disclosure or related attribution of the providers.

In addition, the number of personal certifications and the number of DeGIR/DGNR training centres for Module A were recorded. In addition to the acquisition of 50 module-specific CME points, the granting of personal certification at Level 2 of the DeGIR in Module A requires proof of 150 interventions performed independently in Module A and a successfully-passed specialist examination for this module. For approval as a training centre, in addition to the availability of an interventional radiologist for vascular medicine certified by DeGIR, proof of annual performance of at least 50 interventions in Module $A$ is required [9]. Centers performing more than 500 interventions per year are considered high-volume facilities.

The data were initially classified according to federal state. In a second step, this was broken down to the level of the administrative districts, or federal states if there are no separate administrative districts. A graphic visualization of the area coverage was created showing the absolute numbers, changes in the figures from 2018 to 2019 and, at the level of the federal states, a visualization of the interventions per million inhabitants. Visualization of the centres was carried out at the municipality level.

A descriptive statistical analysis employed the $R$ Statistics program (R version 3.6.3 (2019-03-11) - “Great Truth") [13]. Graphical representation was created using the following software:

Creative Commons Attribution 3.0 License (www.geonames.org), Geojson Deutschland (https://github.com/isellsoap/deutschland GeoJSON)

Technical data:

(c) German Federal Office of Statistics data according to Section 21 of the Hospital Remuneration Act, 2016.

(c) Federal Statistical Offices and state census data: 2011 census Basic data:

(c) EuroGeographics (2013) European Boundary Map 2013 at 1:3000 000 scale

(C) GeoBasis-DE/BKG (2018) Germany administrative boundaries 2017 at $1: 250000$ scale

(c) GeoBasis-DE/BKG (2018) WebAtlasDE

Genesis-Online; Data license dl-de/by-2-0), Openstreetmap (https://www.openstreetmap.org/copyright (c) OpenStreetMap contributors), Folium/Geopandas/Shapely/Python (map creation).

\section{Results}

In 2019 there were a total of 461 DeGIR-certified interventional radiologists practicing vascular medicine in Germany. In 2018, 56036 interventional radiological interventions in Module A were documented at 225 institutions. The number of documented interventions in Module A rose by 3.3 \% to 57732 in 2019, performed at 228 centres ( $\triangleright$ Fig. 1 ). The median number of procedures documented per centre was 144.5 in 2018 and 162.0 in 2019. The number of high-volume centres with more than 500 documented procedures per year remained constant from $2018(n=35)$ to $2019(n=36)$. The maximum number of Module A procedures documented at one centre was $n=1623$ in 2018 and $n=1335$ in 2019. In both 2018 and 2019, 139 DeGIR/DGNR training centres were accredited for Module A.

Interventional radiological procedures for vascular revascularization were used throughout Germany. At the administrative district level, a median (range) of 2324 (323-12 518) interventional radiological revascularizations per district were documented in 2018 and 2019; these procedures were performed in all districts. - Fig. 2 illustrates the area-wide care at the administrative district level. Normalized to per million inhabitants, an average of 1295 Module A interventional radiological interventions were carried out across Germany in 2018/19. The number of documented interventions fluctuated between 954.4 per million inhabitants in Bremen and 3550.6 per million inhabitants in Saarland ( $\bullet$ Fig. $\mathbf{3}$ ).

\section{Discussion}

Peripheral artery disease (PAD) is a common condition with high socio-economic relevance. The number of interventional treatments for PAD has been steadily increasing for years ( $\mathbf{F i g . 4 )}$ [14]. Comprehensive availability of treatment has therefore assumed great importance. Quality-assured provision of this medical service, for example ensured by an institutional and personal certification program, is one of the basic tools for this. Accordingly, at the European level, for example, the Cardiovascular and Interventional Society of Europe (CIRSE) requires this as a basic component of high-quality service provision in interventional radiology [15]. There is consensus that the importance of structured training and appropriate performance quality control in interventional radiology cannot be overestimated [16]. In Germany, this is represented by the modular DeGIR/DGNR training system and the Quality Assurance Registry for Interventional Radiology.

Analysis of 2018/2019 data of the DeGIR Quality Assurance Registry for Interventional Radiology showed stable nation-wide provision of vascular recanalizations performed using interventional radiology in Germany. The distribution of the DeGIR-certified interventional radiologists in vascular medicine as well as the availability of the documenting centres essentially follows the distribution of hospitals in Germany, as has already been shown for hemorrhage embolization [12]. Accordingly, regions with few hospitals also have fewer certified interventional radiologists or centres participating in related quality assurance programs. Consideration of the more closely-knit level of government districts reveals no white spots, underscoring the availability of widespread coverage.

Since documentation of performance data is done on a voluntary basis, informational gaps can be assumed, including the number of recording centres and documented interventions per centre. With almost 605 hospitals in Germany with a senior physician for radiology and 228 centres in the same year that recorded Module A services in the DeGIR registry, it can be assumed that there is a relevant number of facilities providing but not documenting services. Furthermore, it cannot be assumed that each centre fully records its services. The large difference in the maxi- 


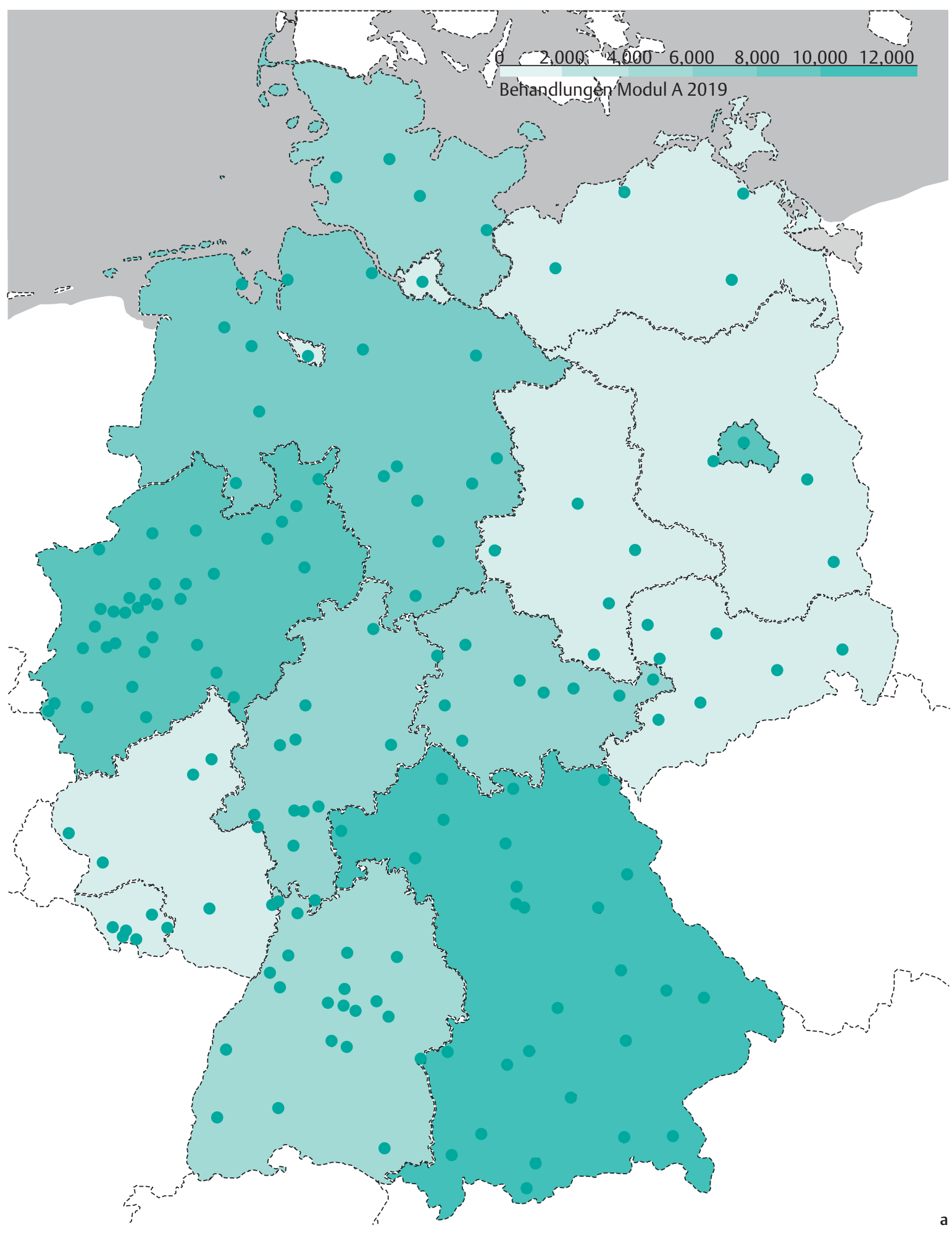

- Fig. 1 Colour-coded display of documented procedures from Module A for the year 2019 a and the change in procedural volume from 2018 to 2019 b. Each dot indicates a municipality with at least one documenting centre. 


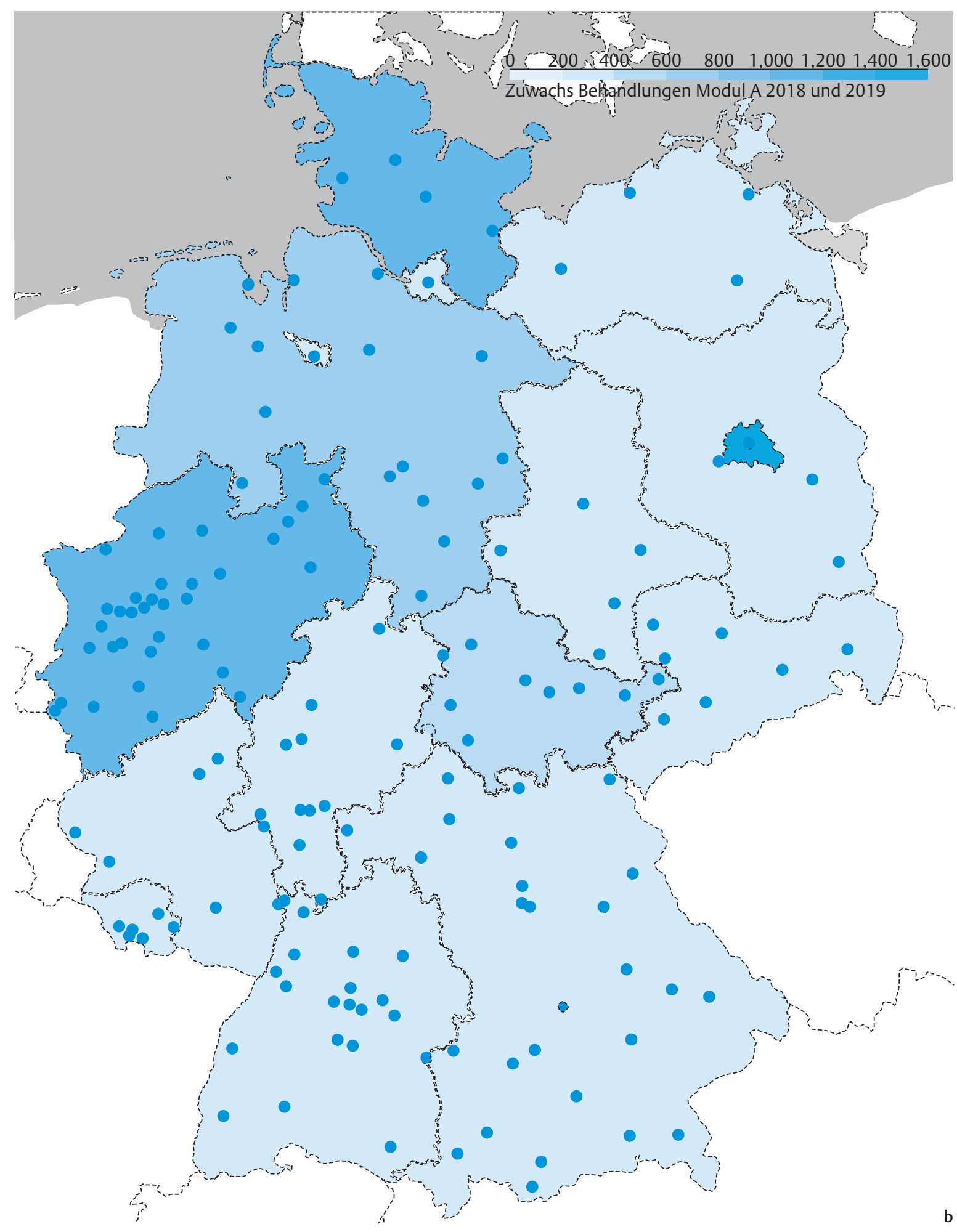

Fig. 1 Colour-coded display of documented procedures from Module A for the year 2019 a and the change in procedural volume from 2018 to 2019 b. Each dot indicates a municipality with at least one documenting centre. 


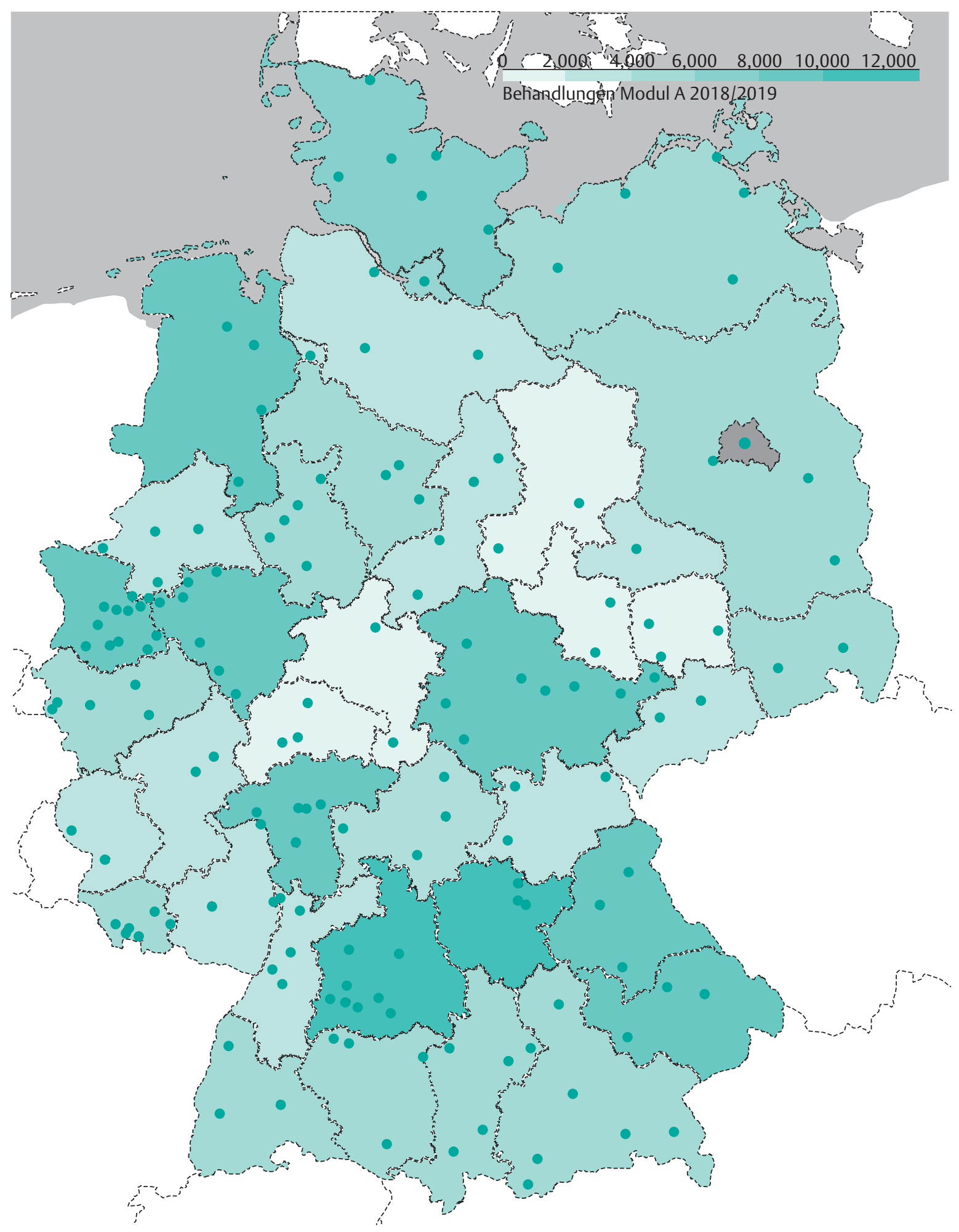

- Fig. 2 Colour-coded map of the aggregated procedure volume from Module A for the years 2018 and 2019 based on administrative districts. In all districts there were centres documenting interventional procedures according to the DeGIR/DGNR quality standards. This figure illustrates the nationwide availability of high quality interventional radiology services for revascularization. Each dot indicates a municipality with at least one documenting centre. 


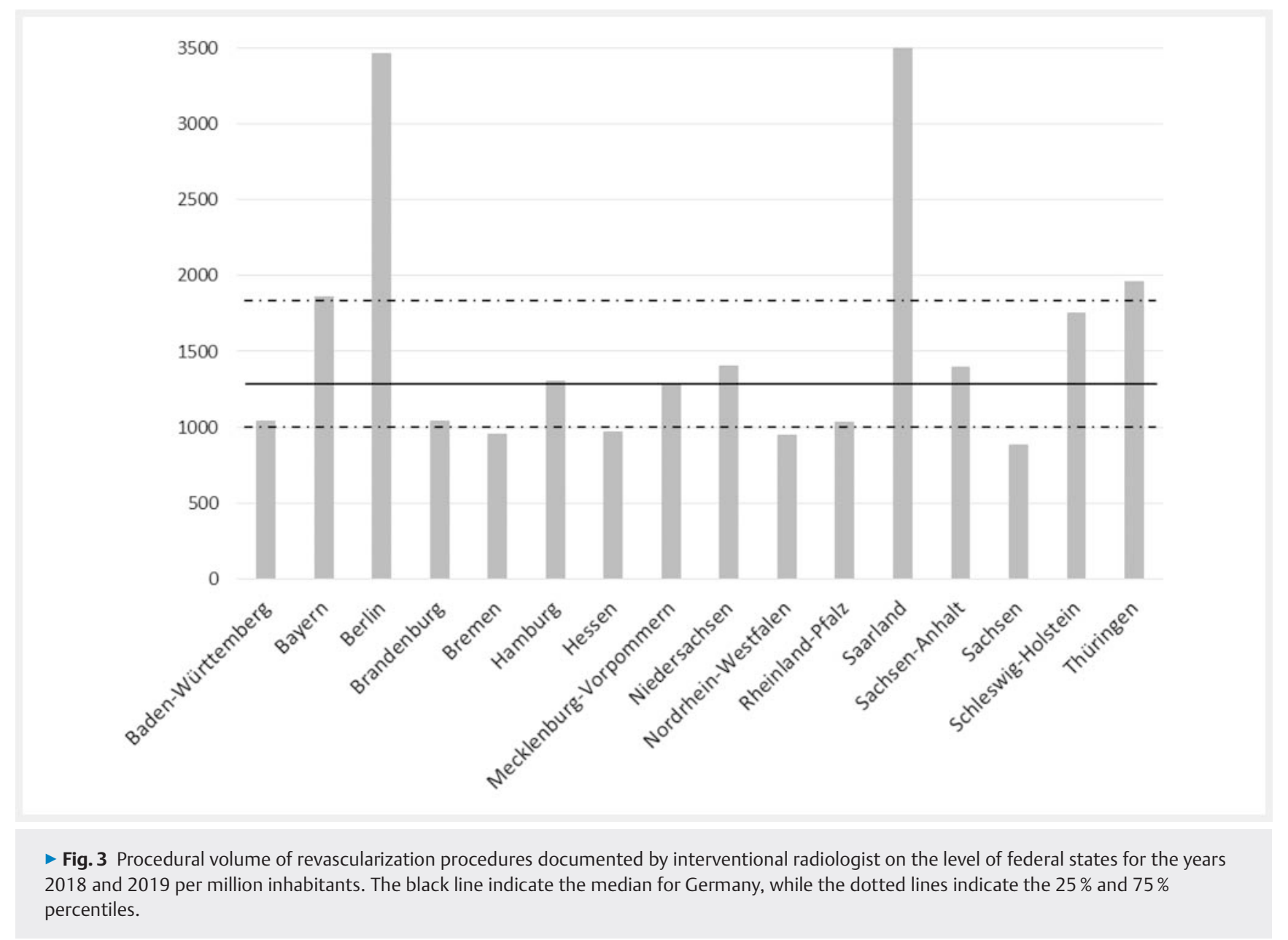

mum number of services recorded per centre between 2018 and 2019 supports this assumption. Based on available data, an estimation of the magnitude of these deviations is not possible. Possible reasons for these documentation gaps may include the time required to record services, costs associated with participation in the DeGIR Registry, as well as technology and vendor change of the Registry that occurred between 2017 to 2018, with the necessity of a new contract.

In addition to differences inherent in the structure of the German hospital landscape, however, analysis of the figures and maps shows clear regional differences when the distribution of interventions is normalized to regional population figures. As previously shown for embolization treatments [12], multifactorial causes can be assumed for these differences. Individual regions, especially Berlin and Saarland, have documented performance figures that are more than double the national average. This may be due to geographic reasons, such as increased or lack of patient mobility. For example, a very large city-state such as Berlin with several maximum-care hospitals can more easily generate patients from the local region, especially if the wider surrounding area has a lower hospital density. Furthermore, in low-population or small regions, even one or two high-volume centres can have a large effect which correspondingly distorts statistics. It can also be assumed that regional differences with regard to the provision of vascular medical disciplines such as angiology and vascular surgery have an effect on the documented performance density of interventional radiological vascular recanalizations. A similar effect can be due to differences in referral behavior depending on the department to which revascularizing interventions are referred.

The use of Module A of the DeGIR/DGNR certification as a surrogate for interventional vascular recanalization presents some ambiguity in comparison with total recanalization interventions performed in Germany, which are essentially summarized in OPS Group 8-836. Nevertheless, it can be ascertained that more than $18 \%$ of all procedures performed in Germany in this treatment group are documented in the DeGIR Registry in 2018 and 2019, with an upward trend. Federal health reports indicate the latter at 307044 (2018) and 310026 (2019) procedures from OPS group 8-836 [14, 17]. It can be assumed that the proportion of procedures documented in the DeGIR Registry is even greater, as more than one procedure from OPS group 8-836 is coded per procedure in the OPS coding for many patients. This is the case, for example, with recanalization of several regions such as the thigh and lower leg, or when various methods such as atherectomy, PTA and stent are combined. Together with the described gaps in the documentation in the DeGIR quality assurance registry, this increases ambiguity in the interpretation of the data. 
300000

250000

100000

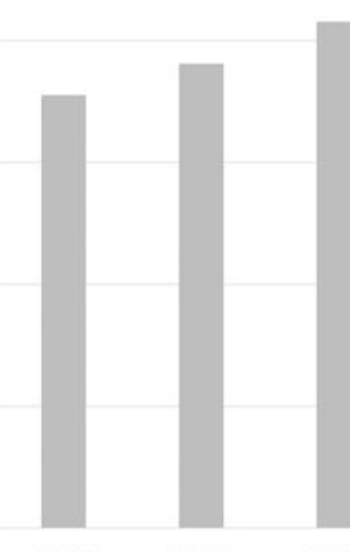

2009

2010

2011

2012

2013

2014

2015

2016

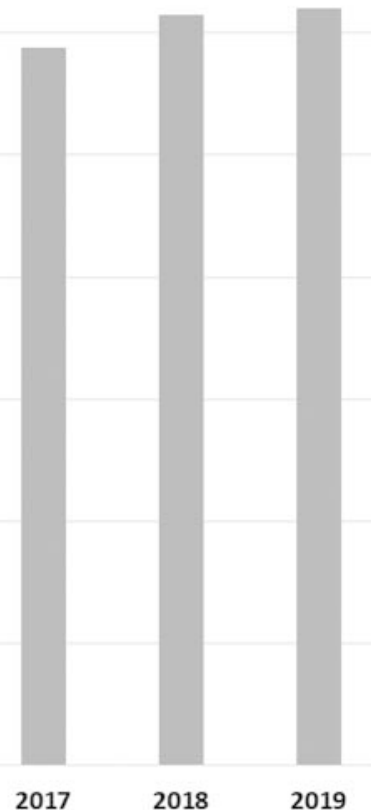

Fig. 4 Bar plot for the development of procedures from the OPS category 8-836 for the last 10 years. The diagram illustrates the steady increase of interventional revascularization procedures.

The regional disparities evident from the coverage map may be reduced in the future as the training situation for interventional radiologists continues to improve. The number of DeGIR training centres in Germany is increasing, and in 2018 and 2019 there were already 139 DeGIR training centres available for Module A interventions. Thus the number of qualified and certified interventional radiologists for vascular medicine can continue to increase based on a solid training infrastructure, which in the intermediate term will benefit structurally weaker and less populous regions.

In summary, it can be stated that in Germany - documented by a structured quality assurance program - there is comprehensive care of PAD by specifically trained and certified interventional radiologists. This benefits patients, who are thus offered highlyqualified care throughout the country.

\section{Conflict of Interest}

The authors declare that they have no conflict of interest.

\section{References}

[1] Statistisches Bundesamt (Destatis). Diagnosedaten der Krankenhäuser ab 2000 (Fälle/Sterbefälle, Fälle je 100000 Einwohner). Gliederungsmerkmale: Jahre, Wohnsitz, Alter, Geschlecht, Verweildauer, ICD-4-Steller, Art der Standardisierung. https://www.gbe-bund.de/gbe/pkg_isgbe5. prc_menu_olap?p_uid=gasts\&p_aid=31256798\&p_sprache $=$ D\&p_help=3\&p_indnr $=703 \& p \_i n d s p=\& p \_i t y p=H \& p \_f i d=$ Zugriff: 28.03.2021
[2] Diehm C, Schuster A, Allenberg JR et al. High prevalence of peripheral arterial disease and co-morbidity in 6880 primary care patients: crosssectional study. Atherosclerosis 2004; 172: 95-105

[3] Sigvant B, Wiberg-Hedman K, Bergqvist D et al. A population-based study of peripheral arterial disease prevalence with special focus on critical limb ischemia and sex differences. J Vasc Surg 2007; 45: 11851191

[4] Moutinho M, Simões I, Rodrigues S et al. Global Impact of Peripheral Obstructive Arterial Disease in Portugal: An Eight Year Study. Acta Med Port 2019; 32: 348-354

[5] Norgren L, Hiatt WR, Dormandy JA et al. Inter-Society Consensus for the Management of Peripheral Arterial Disease (TASC II). Eur J Vasc Endovasc Surg 2007; 33 (Suppl. 1): S1-S75

[6] Becker F, Robert-Ebadi H, Ricco JB et al. Chapter I: Definitions, epidemiology, clinical presentation and prognosis. Eur J Vasc Endovasc Surg 2011; 42 (Suppl. 2): S4-S12

[7] Conte MS, Pomposelli FB, Clair DG. Society for Vascular Surgery Lower Extremity Guidelines Writing Group et al. Society for Vascular Surgery practice guidelines for atherosclerotic occlusive disease of the lower extremities: management of asymptomatic disease and claudication. J Vasc Surg 2015; 61 (Suppl. 3): 2S-41S

[8] Malyar N, Fürstenberg T, Wellmann J et al. Recent trends in morbidity and in-hospital outcomes of in-patients with peripheral arterial disease: a nationwide population-based analysis. Eur Heart J 2013; 34: 27062714

[9] Landwehr P, Reimer P, Bücker A et al. DeGIR-/DGNR training programme in interventional radiology and neuroradiology. Vasa 2017; 46: 494-495

[10] Mahnken AH, Bücker A, Hohl C et al. White Paper: Curriculum in Interventional Radiology. Fortschr Röntgenstr 2017; 189: 309-311 
[11] Berlis A, Morhard D, Weber W. Flächendeckende Versorgung des akuten Schlaganfalls im Jahr 2016 und 2017 durch Neuro-Radiologen mittels mechanischer Thrombektomie in Deutschland anhand des DeGIR/ DGNR-Registers. Fortschr Röntgenstr 2019; 191: 613-617

[12] Nadjiri J, Schachtner B, Bücker A et al. Flächendeckende Versorgung mit radiologisch durchgeführten gefäßverschließenden Maßnahmen zur interventionellen Behandlung von Blutungen in Deutschland in den Jahren 2016 und 2017 - Eine Analyse der DeGIR-Registerdaten. Fortschr Röntgenstr 2020; 192: 952-960

[13] R Core Team. R: A language and environment for statistical computing. R Foundation for Statistical Computing. Vienna, Austria, 2020 https://www.R-project.org/

[14] Gesundheitsberichterstattung des Bundes. Operationen und Prozeduren der vollstationären Patientinnen und Patienten in Krankenhäusern (Wohnort/Behandlungsort). Gliederungsmerkmale: Jahre, Region, Alter,
Geschlecht. https://www.gbe-bund.de/gbe/pkg_olap_tables. prc_set_hierlevel?p_uid=gast\&p_aid=3616918\&p_sprache= D\&p_help=2\&p_indnr=662\&p_ansnr=29398852\&p_version= 4\&p_dim=D.390\&p_dw=43173\&p_direction=drill Zugriff: 28.03 .2021

[15] Tsetis D, Uberoi R, Fanelli F et al. The Provision of Interventional Radiology Services in Europe: CIRSE Recommendations. Cardiovasc Intervent Radiol 2016; 39: 500-506

[16] Belli AM, Reekers JA, Lee M. The importance of curriculum-based training and assessment in interventional radiology. Cardiovasc Intervent Radiol 2014; 37: 8-10

[17] Statistisches Bundesamt (Destatis). Gesundheit - Fallpauschalenbezogene Krankenhausstatistik (DRG-Statistik) Operationen und Prozeduren der vollstationären Patientinnen und Patienten in Krankenhäusern (4-Steller) - 2019. Wiesbaden: Statistisches Bundesamt. 2020: 26 